medicine and family planning and the impact of sexually transmitted diseases on the provision of contraceptives in the specialties. ${ }^{45}$ Until recently family planning clinics focused on providing a service that enabled men and women to prevent or to plan pregnancies. The problem of genital infections was seen as secondary. In genitourinary medicine, however, the emphasis has been on diagnosing and treating sexually transmitted diseases in both the patient and his or her partners; contraception has been regarded only as a means of preventing sexually transmitted diseases.

More recently the emergence of HIV has sharply focused attention on the need for an effective contraceptive method that protects against both infection and pregnancy. Although the public has been made increasingly aware of sexually transmitted diseases and their prevention, there is concern that a move to a barrier method is a move to a less reliable contraceptive. The "double Dutch" method-using a condom and an oral contraceptive-is the only effective protection against both pregnancy and sexually transmitted diseases. ${ }^{6}$ If a barrier method is used alone men and women must be made aware of postcoital contraception.

Sexually active women and men need to be given straightforward, factual information about the risks of sexual activity and the opportunity to discuss such matters in an appropriate environment. This process should start in schools as part of the personal, social, and health education curriculum. Professionals working in reproductive health care should participate in such programmes.

Although providing all sexual health services under one roof may be the ideal, it is unlikely to be achievable for most health authorities. ${ }^{2}$ Collaboration by those who deliver sexual health care may be another way of providing people with appropriate care and treatment. A coordinated sexual health service in both family planning and genitourinary medicine is urgently needed-especially as those at most risk of genital infection and unintended pregnancy are aged under 25.

Collaboration between these two specialties could be achieved without undue cost and organisational complexity. The sharing of nursing and medical staff ensures that staff disseminate their knowledge and training. All family planning clinics should have facilities to screen for vaginal and cervical infections and an agreed protocol for referring patients to genitourinary medicine. Feedback, including to the general practitioner when confidentiality allows, would ensure continuing collaboration. Similarly, family planning services should be made available to people attending genitourinary medicine clinics. Continuing medical education for all staff, with combined meetings, would ensure a coordinated approach to the sexual health care of patients seen in the two departments. Patients would then be referred to a service in which nursing and medical staff had knowledge of, and confidence in, both settings.

Such a model of coordinated and integrated health care seems a sensible target for other specialties that deal with sexual health problems. All doctors and nurses faced with patients with sexual health problems should know their limitations and refer patients when necessary.

YVONNE STEDMAN Consultant in family planning and reproductive health care The South Worcestershire Community NHS Trust,

Worcester WR1 3DB

MAX ELSTEIN Professor

Department of Obstetrics and Gynaecology,

University Hospital of South Manchester,

Manchester M20 2LR

\footnotetext{
1 Department of Health. The health of the nation. Key area handbook. HIVIAIDS and sexual health London: DoH, 1992

2 Greenhouse P. A sexual health service under one roof: setting up sexual health services for women. foumal of Maternal and Child Health 1994;19:228-33.

3 Stedman $Y$, Higgins $S$, Chandiok S. The management of genital infection in women attending family planning clinics in the north west of England. British fournal of Family Planning (in press).

4 Cates W Jr, Stone C. Family planning-sexually transmitted diseases and contraceptive choice: literature update. Part I. Fam Plann Perspect 1992;24:75-84.

5 Cates $\mathrm{W} \mathrm{Jr}$, Stone C. Family planning - sexually transmitted diseases and contraceptive choice: literature update. Part I. Fam Plann Perspect 1992;24:122-8.

6 Doppenberg $\mathrm{H}$. Contraception and sexually transmitted diseases: what can be done? Experiences and thoughts from the Netherlands. British foumal of Family Planning 1993;18:123-5.
}

\title{
Learning medicine in the community
}

\section{Learners should be where the patients are}

and St Mary's Hospital in London..$^{5}$ This week's journal contains accounts of how the Cambridge approach provided Mandy Wharton with "a rich environment in which to anchor ... teaching of disease, health, and clinical skills" (p 407) ${ }^{4}$ and how house officers in general practice gain insight into primary care services and receive substantially more teaching and clinical time than hospital colleagues (p 369). ${ }^{6}$ If these initiatives are so satisfactory why is the move to community based learning of medicine so slow? This problem and suggested solutions are explored in Widening the Horizons of Medical Education, recently published by the King's Fund. ${ }^{3}$

In the report researchers from King's College, London, explore the implications of transferring a substantial amount of undergraduate medical education into the community. They advocate managing educational change by consultation, and describe how they carried out this consultation in and around King's College Hospital. They report the views of patients, general practitioners, students, and other interested parties. Patients and carers wanted to participate in the teaching of medical students; and general practitioners were also enthusiastic but saw the need for protected time, training, and support; students were initially anxious about potential 
isolation, breaking with tradition, and the quality of teaching but became more positive when they considered the implications of learning in the community. The authors say that "telling is selling"; discussion with interested groups tended to increase support.

One important barrier to any change of site for medical education is the cumbersome funding system, whereby the complex funding provided jointly by the Department of Health and the Higher Education Funding Council is divorced from educational accountability, which is itself unclear. In addition, the provision of the service increment for teaching and research is governed by rules that do not allow the increment to be transferred outside the hospital system. At present the Department of Health (through the family health services authorities) provides small fees for the teaching of undergraduates in general practice but makes no formal provision for the supervision of house officers. The report from King's College recommends that medical education should be both funded and monitored for quality by the Higher Education Funding Council. Medical schools would allocate funds to the various sites where students learn.

Two further proposals should be considered. Firstly, teachers need training to develop their abilities. This is a task already taken seriously in the education of postgraduate trainees in general practice, and without it consistently high quality teaching is unlikely to be maintained in any context. ${ }^{7}$ Because formal training in educational skills has been largely absent in hospital settings, reorganisation of the present funding system might not cover staff development and new ways to teach teachers might have to be devised.

Secondly, teaching and research in the community requires an infrastructure, including space, administration, and information technology. Teachers and researchers in general practice need an ability to appraise evidence from scientific research and clinical examination. Because they share these needs and research is likely to be more effective when clinicians and researchers share priorities and values, ${ }^{8}$ closer links between clinical teachers, researchers, and clinicians should also pay dividends in the development of primary care. One way of doing this would be to set up academic practices with an additional partner to reduce service loads and contracts to provide both teaching and research. ${ }^{9}$ This would also help to prevent the potential isolation of students outside a hospital base but would again require funding additional to that proposed at King's College.

In all these developments there is a risk that primary care departments may be seen as competing with hospital specialties and basic sciences for both curricular time and funding. It is vital that all change is underpinned by a clear educational philosophy related to the aims of the overall curriculum. Hospital specialists also serve the community, but their views were not sought in the King's College project. Examples of good teaching in the present curriculum and house officer posts should not be lost but reinforced. Combined staff development sessions, such as those reported at King's College, could both reduce any tension and improve the confidence of staff working outside the hospital setting. Finally, all change must be carefully evaluated. Evidence based education is as important as evidence based medical practice.

\section{JENNY FIELD \\ Senior lecturer \\ ANN-LOUISE KINMONTH \\ Professor}

Primary Medical Care,

University of Southampton,

Southampton SO1 6ST

\footnotetext{
1 Silver GA. Victim or villain. Lancet 1983;ii:960.

2 General Medical Council. Tomorrow's doctors. London: GMC, 1993.

3 Seabrook M, Booton P, Evans T, eds. Widening the horizons of medical education. London: King's Fund, 1994.

4 Wharton M. Clinical training in the community: a holistic approach. BMF 1995;310:407.

5 Harris CM, Dudley HAF, Jarman B, Kidner PH. Preregistration rotation including general practice at St Mary's Hospital Medical School. BMF 1985;290:1797-9.

6 Wilton J. Preregistration house officers in general practice. $B M \mathcal{F}$ 1995;310:369-72.

7 Entwistle N. The impact of teaching on learning outcomes in higher education: a literature review. Sheffeld: Committe of Vice Ching on learning outcomes in hish

Haines A, Jones R. Implementing findings of research. BMF 1994;308: 1488-92.

9 Rous A, Jones R. Implementing findings of research. BMy 1994308:1488-92.

Royal College of General Practitioners. Conference of academic organisations in general practic Research and general practice. London: RCGP, 1994.
}

\section{The shaken infant syndrome}

\section{Parents and other carers need to know of its dangers}

In children less than 1 year, non-accidental injury is the commonest cause of serious head injury ${ }^{1}-$ much of it resulting from shaking and impact. Last week saw the launch of a leaflet, "Handle with Care," produced by the National Society for the Prevention of Cruelty to Children and the Department of Health, in response to increasing professional concern over the dangers of shaking babies.

John Caffey first drew attention to the association of fractures of the long bones and subdural haematomas, and he implicated whiplash injury as the cause of the intracranial trauma. ${ }^{2}$ It is accepted that shaking alone can cause the brain damage, ${ }^{3}$ and it is now recognised that the infant's head also undergoes rotational forces as well as whiplashing during shaking. ${ }^{4}$ Injuries may result from single or multiple episodes of shaking.

The severity of the shaking force is such that shaking injuries cannot occur in any form of playful activity (as Caffey originally suggested ${ }^{2}$ ). A recent description of the act of shaking states that it is so violent that neutral observers would recognise it as dangerous. ${ }^{5}$

The clinical presentation of a shaking injury may not suggest abuse-signs include irritability, lethargy, vomiting, convulsions, apnoea, shock, and fluctuating consciousness. The history may be confusing if the adult bringing the child to medical attention has no knowledge that the child has been shaken or withholds information. Shaking injuries that produce subtle clinical changes may never be brought to medical attention. There may be a delay in seeking medical help because the perpetrator believes that the shaken child is asleep rather than unconscious. After a variable time, the infant will develop signs of cerebral irritation, cerebral oedema, or intracranial haemorrhage. ${ }^{4}$ Acute deterioration, convulsions, or respiratory or circulatory arrest may follow.

Although clinical examination of the infant may reveal bruising or other evidence of neglect in addition to the neurological signs, it often shows nothing unusual. Retinal haemorrhages are present in between $50 \%$ and $80 \%$ of patients, ${ }^{6}$ and when other causes have been excluded are virtually pathognomonic of child abuse. Ideally, the fundi should be examined by an ophthalmologist who frequently examines children. If the cerebrospinal fluid is examined frank haemorrhage or xanthochromia indicate acute or recent 